patient had polyclonal hypogammaglobulinaemia, but levels were not measured in 11/42 (26\%) with potential features of CVID.

Conclusion Our study identified a cohort of patients with a diagnosis of sarcoidosis and features associated with CVID. We found that immunoglobulins were not being routinely measured during the work-up of patients with sarcoidosis as recommended by the Map of Medicine. Recent review of 28 local CVID patients identified two who were initially misdiagnosed with sarcoidosis. In one case this misdiagnosis persisted for 8 years. Granulomatous CVID is uncommon, but respiratory physicians should ensure that their routine work-up for sarcoidosis excludes this treatable condition.

\section{P92 C REACTIVE PROTEIN AS A PREDICTIVE INDICATOR OF TREATMENT AND DISEASE PROGRESSION IN PATIENTS WITH SARCOIDOSIS: A RETROSPECTIVE OBSERVATIONAL COHORT STUDY IN THE WEST OF IRELAND}

doi:10.1136/thoraxjnl-2011-201054c.92

M J McDonnell, I Saleem, R Rutherford, A O'Regan, J J Gilmartin. University Hospitals Galway, Galway, Ireland

Introduction $\mathrm{C}$ reactive protein (CRP) is an acute-phase protein synthesised in response to tissue damage or inflammation. Previous studies evaluating the role of CRP in sarcoidosis have focussed on disease monitoring. Adequate markers to determine predictors of progression in sarcoidosis are currently lacking.

Objectives The aim of this retrospective observational study is to evaluate the utility and practical application of baseline serum CRP in predicting treatment indication and disease severity in a welldefined sarcoidosis population over a 26-year follow-up period.

Methods We reviewed the clinical, biochemical, radiological and physiological findings in all confirmed sarcoidosis patients attending a regional referral centre between 1983 and 2009. Disease progression was defined in two ways: decline in lung function as per Hunninghake criteria ( $>15 \%$ reduction in baseline $\mathrm{FEV}_{1} \%$ and/or $>10 \%$ decline in baseline DLCO $\%$; and radiological progression (defined as worsening stage of disease and/or development of bronchiectasis or cavitation). Indication for treatment was defined as need for corticosteroid treatment throughout duration of followup. Correlation coefficients and multiple logistic regression (MLR) analysis were performed to determine independent baseline variables relating to outcome. Results are expressed as OR, 95\%-CIs and p-values.

Results $328 / 409$ (80.2\%) of sarcoidosis patients were suitable for inclusion, $46.6 \%$ of whom had an abnormally elevated CRP at presentation. MLR analysis of presenting characteristics with baseline CRP showed strong associations with Löfgren's syndrome $(p=0.002)$ and FVC $\%(p=0.009)$, consistent with previously published data. In terms of predicting outcomes, CRP was found to be an independent predictor of both radiological progression and physiological deterioration ( $\mathrm{p}=0.026$ and 0.048 respectively). Other independent indices for radiological progression were smoking status, Löfgren's syndrome and Scadding CXR stage at presentation $(p=0.035,0.002$ and $<0.001$ respectively). DLCO $\%$ was shown to be a further independent predictor of physiological decline $(p=0.015)$.

Conclusion This is one of the largest clinical studies investigating the predictive influence of CRP in sarcoidosis. The data suggests a role for CRP as a predictive indicator of physiological deterioration and radiological progression. Therefore, a subset of chronic sarcoidosis patients with high baseline CRP at presentation may benefit from closer monitoring and extra attention to parameters of physiological and radiological decline.

\section{Integrated respiratory care}

P93 HOSPITAL ADMISSION AVOIDANCE FOR PEOPLE WITH EXACERBATIONS OF CHRONIC OBSTRUCTIVE PULMONARY DISEASE (COPD) THROUGH COLLABORATIVE WORKING BETWEEN SUFFOLK COPD SERVICES AND EAST OF ENGLAND AMBULANCE SERVICE

doi:10.1136/thoraxjnl-2011-201054c.93

${ }^{1} \mathrm{~L}$ J Pearce, ${ }^{2} \mathrm{M}$ Broad, ${ }^{1} \mathrm{~T}$ B Pulimood, ${ }^{1} \mathrm{CM}$ Laroche. ${ }^{1}$ West Suffolk Hospital NHS Trust, Bury St Edmunds, UK; ${ }^{2}$ East of England Ambulance Trust, Cambourne, UK

Introduction BTS Guidelines recommend that admission avoidance schemes should be available for patients with exacerbations of COPD. The Suffolk COPD Service was established in 2009, operating 365 days/year. One strand of the service aims to avoid inappropriate hospital admission by encouraging GPs to refer to the service rather than sending patients into hospital. However, despite wide publicity hospital admission rates remained high. Review of 24 COPD hospital admissions suggested that $50 \%$ would have been suitable for admission avoidance through Suffolk COPD Services. $95 \%$ of these patients had been brought in to A\&E by ambulance. Feasibility of direct ambulance referral into Suffolk COPD Services was discussed with ambulance personnel.

Method A business case, working protocol and pathway were developed jointly, along with a robust clinical governance system. It was planned that a member of the Suffolk COPD Nursing team would visit the patient within $4 \mathrm{~h}$ of referral. Approval was gained from the Local Medical Council and Expert Clinical Steering Group. The system was launched following wide publicity and training of both ambulance and nursing staff.

Results The first successful referral was received 40 min after the launch. In the first year 83 referrals were received, of which only eight were inappropriate and requiring redirection to other services or hospital admission.

Advantages of ambulance referral system:

- Reduction in ambulance call cycle time by up to $30 \mathrm{~min}$

- Increased ambulance personnel COPD knowledge

- Development of patient group directives

- Improved team working/collaboration across services

- Ability to discharge duty of care to a specialist community service

- Increased admission avoidance

- People cared for in own home

- "Self supported" care encouraged

- Cost efficient

Conclusion $73 \%$ were admissions avoided compared to the $50 \%$ which had been predicted. The collaboration was a successful model of service delivery, reducing hospital admissions by the seamless transition of the duty of care from the ambulance service to the Suffolk COPD Services, who supported the patient at home.

Abstract P93 Table 1 Period from July 2010 to June 2011

\begin{tabular}{lllll}
\hline $\begin{array}{l}\text { Total } \\
\text { referrals }\end{array}$ & $\begin{array}{l}\text { Appropriate } \\
\text { referrals }\end{array}$ & $\begin{array}{l}\text { Admitted at } \\
\text { nurse 1st visit }\end{array}$ & $\begin{array}{l}\text { Admitted } \\
\text { within 2/52 }\end{array}$ & $\begin{array}{l}\text { Total } \\
\text { admissions }\end{array}$ \\
\hline 83 & $75(90 \%)$ & $10(13 \%)$ & 10 & $20(27 \%)$ \\
\hline
\end{tabular}

\section{REFERENCE}

1. Intermediate care-hospital-at-home in chronic obstructive pulmonary disease: British Thoracic Society guideline. Thorax 2007:62:200-10. 